\title{
(Q) Enablers and barriers to clinical leadership in the labour ward of district hospitals in KwaZulu-Natal, South Africa
}

\author{
Solange Mianda, ${ }^{\circledR}$ Anna Silvia Voce
}

Public Health Medicine, University of KwaZulu-Natal School of Nursing and Public Health, Durban, South Africa

\section{Correspondence to}

Dr Solange Mianda, Public Health Medicine, University of KwaZulu-Natal School of Nursing and Public Health, Durban, KwaZulu-Natal, South Africa;

solange.zoe60@gmail.com

Received 28 November 2018 Revised 17 June 2019 Accepted 25 June 2019 Published Online First 20 July 2019
D) Check for updates

(C) Author(s) (or their employer(s)) 2019. Re-use permitted under CC BY-NC. No commercial re-use. See rights and permissions. Published by BMJ.

To cite: Mianda S, Voce AS BMJ Leader 2019:3:75-80.

\begin{abstract}
Introduction and background Like many health systems in low-income and middle-income countries, the South African health system has failed to decrease both maternal and perinatal mortality significantly, especially in district hospitals. Inappropriately trained healthcare providers and poor clinical leadership are repeatedly linked to healthcare providers' preventable factors contributing to most maternal and perinatal deaths. Clinical skills of healthcare providers have been largely addressed, while clinical leadership remained neglected. One strategy implemented recently to support clinical leadership is the introduction of District Clinical Specialist Teams (DCSTs). Clinical leadership in the labour ward of district hospitals in KwaZulu-Natal (KZN) is conceptualised as an emergent phenomenon arising from dynamic interactions in the labour ward and the broader health system, converging to attain optimal patient care.
\end{abstract}

Aim To evaluate the enablers and barriers to clinical leadership in the labour ward of district hospitals. Method Iterative data collection and analysis, following the Corbin and Strauss grounded theory approach, was applied. In-depth interviews were carried out with the midwifery members of the DCSTs in KZN. The emergent enablers and barriers to clinical leadership were presented and discussed at a workshop with broader midwifery representation, leading to a final classification of enablers and barriers to clinical leadership.

Results and conclusion Enablers and barriers to clinical leadership arise as a result of emergent dynamic interactions within the labour ward and the broader health system, located at policy, organisational, team and individual healthcare provider levels, with the policy context as the overriding factor framing the implementation of clinical leadership.

\section{INTRODUCTION}

The South African health system is undergoing reform reflecting the state of many other developing health systems in low-income and middle-income countries (LMICs). ${ }^{1}{ }^{2}$ Like many health systems in LMICs, the South African health system has failed to decrease both maternal and perinatal mortality significantly, especially in district hospitals, a primary level of care, offering comprehensive essential obstetric care. ${ }^{3-8}$ The persistent maternal and perinatal mortality in South Africa is attributed to poor or lack of leadership at country, district and institutional levels. ${ }^{9} 10$

In district hospitals, inappropriately trained healthcare providers and poor clinical leadership are repeatedly linked to healthcare providers' preventable factors contributing to most maternal and perinatal deaths. ${ }^{11-13}$ While clinical skills of healthcare providers have been largely addressed, clinical leadership remained neglected. ${ }^{12-16}$

Recently, the National Department of Health introduced District Clinical Specialist Teams (DCSTs) as a strategy to improve maternal and child outcomes in district hospitals, through the provision of support for clinical leadership and governance. ${ }^{17}$ However, the provision of support by DCSTs is an outreach activity from district health offices, where the DCSTs are located, to district hospitals.

In district hospitals, a hierarchy of positional leaders is overall responsible for ensuring clinical leadership. However, the actual provision of clinical leadership at the bedside has been found to be inadequate and ineffective. ${ }^{12} 18-20$ Thus, the provision of clinical leadership within district hospitals requires development and strengthening.

In the labour ward of district hospitals, most deliveries are midwife-led, with doctors on call to deal with complications and emergencies. ${ }^{21}$ Midwives are equipped with the necessary skills to make clinical decisions pertaining to mothers and babies; and should be able to influence care practices at the bedside, and to contribute to effective teamwork and the creation of an enabling work environment. ${ }^{21-23}$ But, often, midwives are neither clear about, nor have been prepared for, the clinical leadership role. ${ }^{2425}$ To enable midwives to provide effective care, it becomes imperative that they understand the clinical leadership role. ${ }^{24}$

Clinical leadership in the labour ward of district hospitals in KwaZulu-Natal (KZN), South Africa, has been conceptualised as an emergent phenomenon arising from dynamic interactions in the labour ward and the broader health system, which converge to attain optimal patient care. ${ }^{26}$

However, the enablers and barriers to the realisation of this conceptualisation of clinical leadership are not well understood.

\section{AIM}

Given the need for the development of clinical leadership in the labour ward of district hospitals in KZN, South Africa, this study was designed to evaluate the enablers of, and barriers to, clinical leadership.

\section{METHODS}

\section{Study design and respondents}

A grounded theory methodology according to Corbin and Strauss ${ }^{27}$ was used to evaluate enablers and barriers to clinical leadership in the labour 
ward of district hospitals. This methodology seeks to generate evidence for a phenomenon where there is little available evidence, ${ }^{27} 28$ and was considered most appropriate in a context where there is a paucity of evidence on the implementation of clinical leadership.

Purposive heterogeneous sampling was implemented to recruit the research participants. Advanced midwifery members of the DCSTs in KZN were selected because of their role in supporting clinical leadership. Advanced midwives in leadership positions in labour wards of district hospitals, academicians responsible for midwifery training in $\mathrm{KZN}$, and district and provincial level representatives from the KZN Department of Health were selected to elicit data from their respective perspective on the enablers and barriers to clinical leadership. The researcher (SM) recruited respondents via telephonic and email invitation.

\section{Procedure}

The study was conducted in two phases:

In Phase I, the researcher (SM) conducted individual in-depth face-to-face and telephonic audio-recorded interviews with eight advanced midwifery members of the DCSTs, in a location of each respondent's choice. Interviews were conducted in English and lasted between 45 min and 1 hour. An interview guide using open-ended questions guided the in-depth interview, ${ }^{29}$ covering enablers and barriers to clinical leadership.

In keeping with the Corbin and Strauss approach to grounded theory, data collection and analysis happened iteratively. ${ }^{28}$ After each interview, transcripts were analysed in three stages. In open coding, transcripts were read and re-read, assigning labels to chunks of data. In the stage of axial coding, codes with similar meaning were grouped together, as were codes that were related to each other. The stage of selective coding led to the identification of major enablers and barriers to clinical leadership. Phase I resulted in the classification of enablers and barriers to clinical leadership at the individual, team, organisational and policy levels.

In Phase II, the authors facilitated a workshop to provide feedback on Phase I of the study and to generate additional insights. Workshop participants comprised all the interviewed advanced midwifery members of the DCSTs (8), advanced diploma midwives in leadership positions in labour wards of district hospitals (5), academicians responsible for midwifery training in KZN (2), and district (1) and provincial (1) level representatives from the Directorate for Maternal, Child and Women's Health in the Provincial Department of Health.

In the workshop, summarised feedback on enablers and barriers to clinical leadership was provided by the authors and discussed by all present. The workshop was video recorded. The researcher (SM) listened to the recording many times to identify

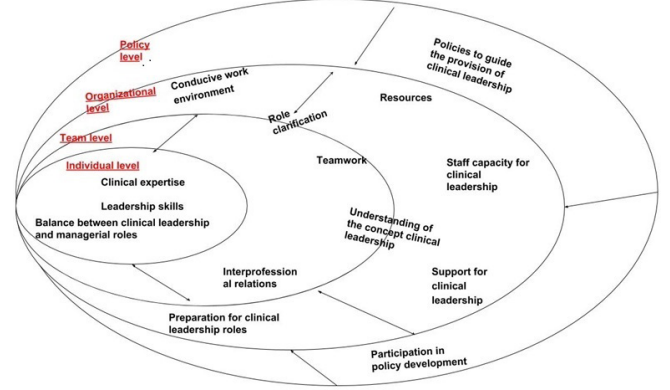

Figure 1 Summary of enablers and barriers to clinical leadership in the labour ward of district hospitals in KZN, South Africa, in 2015. KZN, KwaZulu-Natal.

consensus and divergence on the enablers and barriers to clinical leadership identified in Phase I, as well as to discern different emphases provided by the workshop participants. SM analysed the audio recording of the workshop with a focus on attaining meaning saturation for the categories identified in Phase I. ${ }^{30}{ }^{11}$ Further, the workshop assisted in ensuring trustworthiness of the research findings by introducing member check as a technique for enhancing credibility. ${ }^{32}$ Additional measures to ensure the trustworthiness of the study ${ }^{33}$ is summarised in table 1 .

\section{RESULTS}

Enablers and barriers to clinical leadership in the labour ward of district hospitals in KZN were identified at policy, organisational, team and individual levels, as reflected in figure 1 . The factors identified at the different levels can be either enablers or barriers, depending on whether they are present or not. Although presented separately, the enablers and barriers within and between levels are linked, with much overlap between them.

Enablers and barriers to clinical leadership at the policy level Respondents identified the need for a policy context that supports clinical leadership in the labour ward of district hospitals. Policies are required to guide the training and development for the clinical leadership role. Respondents emphasised the importance of involving clinical leaders in policy development processes to ensure implementation.

Midwives need to be included in policy development; in this way, they are able to ensure that they understand them and use them. (Respondent 7)

When policies and guidelines are developed, clinical leaders need to input on them.... if you engage them (clinical leaders) while you are still developing them (policies) to say: 'guys have a look at these

Table 1 Measures for ensuring trustworthiness

\begin{tabular}{lll}
\hline Constructs & What it ensures & Strategies employed to achieve construct \\
\hline Credibility & $\begin{array}{l}\text { Representation of findings reflect as experienced } \\
\text { by participant perspectives } \\
\text { Covel of confidence that the study's findings are } \\
\text { based on respondent's narratives rather than } \\
\text { potential researcher biases }\end{array}$ & $\begin{array}{l}\text { Member check was used to ensure the credibility of the research findings. } \\
\text { Verbatim quotes have been provided to illustrate findings. } \\
\text { Iterative data collection and analysis was implemented. Corbin and Strauss' } \\
\text { three-stage approach to coding was implemented, ensuring that findings } \\
\text { were grounded in the data. }\end{array}$ \\
$\begin{array}{ll}\text { Process of research is logical, traceable and clearly } \\
\text { documented }\end{array}$ & $\begin{array}{l}\text { A full description of the research method has been provided, describing what } \\
\text { was planned and how it was executed. }\end{array}$ \\
Transferability & $\begin{array}{l}\text { Applicability of findings to other similar settings } \\
\text { and contexts }\end{array}$ & $\begin{array}{l}\text { The study was conducted in district hospitals in a province of South Africa, } \\
\text { a middle-income country, characterised by health inequalities, within a } \\
\text { maturing health system, affecting resourcing, quality of care and health } \\
\text { outcomes. Findings are transferrable to similar contexts. }\end{array}$ \\
\hline
\end{tabular}


policies/guidelines, do you have any input?' This will ensure that they know the policies and implement them. (Respondent 5) get them for 3 months they leave for greener pastures. (Respondent 2)

Support for the role of clinical leadership

Midwives indicated that support from health service managers enabled clinical leadership roles. They expressed that supervision and mentoring were necessary to assist clinical leaders in their roles. Midwives also indicated the need for better communication between the management team and the midwives at the bedside, to support clinical leadership.

When I am talking of support, I am talking about clinical support, like when I (positional clinical leader) am visiting the labour ward, we (positional clinical leader and nursing manager) look at the case together; we manage the case together with frontline healthcare providers that are present, so that they will learn. (Respondent 8)

You need an environment that is conducive to provide clinical leadership. But the environment is not welcoming. (Respondent 4) Clinical leadership is constrained because there are no resources to develop clinical leadership. (Workshop participant)

\section{Service organization}

The organisational context was identified as influencing clinical leadership. Particularly, the shortage of formally appointed clinical leaders was perceived to hinder the provision of effective clinical leadership.

A maternity service in a district hospital is headed by the medical manager. The maternity service, in turn, is divided into wards, for example, antenatal and labour wards, each headed by an operational manager or midwife formally appointed as a clinical leader. (Workshop participant)

There are shortages of formally appointed clinical leaders to all the divisions within maternity, hindering formally appointed clinical leaders to provide effective clinical leadership at the bedside.

I am an operational manager for maternity, which includes antenatal care, nursery, labour ward, postnatal care and high-risk patients. It is not possible for me to provide $100 \%$ clinical leadership in an environment like that. (Workshop participant)

Additionally, respondents identified the need for proper equipment for training and development, for the clinical leadership roles at the bedside.

You need proper equipment to provide clinical leadership. You can't expect effective leadership if there is no equipment (for training and development of leadership roles). (Respondent 4)

\section{Staff capacity for clinical leadership}

High-staff turnover was seen to not allow sufficient time to develop clinical expertise in midwives, limiting shared clinical leadership at the bedside. Even after being equipped with the required skills, healthcare professionals are leaving the labour ward in search of better opportunities, or for fear of litigation, making it difficult to retain skilled healthcare providers. Further, it is not always easy to recruit new healthcare providers due to restrictive recruitment procedures.

There is a fast movement of staff. After you have equipped them (staff) with the required skills, they leave for greener pasture. If you (clinical leader) do not have a stable staff, you are unable to make progress. It is a vicious circle that you are not able to break, not having the quality of staff you desire. (Respondent 3 )

Recruitments procedures are difficult because posts are frozen, you cannot get the staff you need, especially in rural areas, and if you

\section{Preparation for clinical leadership roles}

Preparation for clinical leadership roles is essential for ensuring effective clinical leadership, especially for formally appointed clinical leaders. Induction, in-service training and formal training programmes were considered important parts of the preparation required for clinical leadership roles. The emphasis on what should be covered in the training fell on leadership skills and clinical expertise. Respondents expressed the opinion that training should be provided prior to the formal appointment to the role of clinical leader. Training and support for the clinical leadership role should also be made available after the appointment of clinical leaders.

I think there should be some clinical leadership training before you assume your role as a (formally appointed) clinical leader. (Respondent 4)

Induction is very important especially on the existing (clinical) protocols, guidelines and all the programs that you are going to be responsible for. (Respondent 6 )

I cannot overemphasise ... without in-service training or obstetric drills, you cannot provide better care. So in-service education is important in maternity. (Respondent 7)

Enablers and barriers to clinical leadership at the team level Themes identified at the team level are related to the perceptions of clinical leadership and interprofessional relations in the labour ward.

\section{Perception of the concept of clinical leadership}

Midwives felt that clinical leadership responsibilities in the labour ward were not clearly defined, especially for formally appointed clinical leaders, hampering their ability to engage in clinical leadership activities. One respondents stated the following:

What I am realising is that the clinical leadership responsibilities are not clearly defined. You find the operational manager doing more of managerial duties than clinical duties. (Respondent 3)

Poor understanding of the concept of clinical leadership by formally appointed clinical leaders was reported as a result of the terminologies used in job designations.

They (clinical leaders) were appointed as operational managers. Even the term 'clinical leaders' only came in force with District Clinical Specialist Teams (DCSTs). When you say, 'operational manager', it is equal to the day-to-day running of a department. They (Department of Health) need to change the terminology from 'operational managers' to 'clinical leaders', then it rings a bell. (Respondent 1) 
Respondents reported a prevailing perception that clinical leadership activities fell only within the purview of formally appointed leaders.

I think because the senior managers when they need something in the labour ward, they focus on the one that is having a title and say: 'Can we have this or that?' and then other healthcare providers are reluctant to step in as clinical leaders. (Respondent 6)

\section{Interprofessional relations}

The nature of the care environment in the labour ward was considered essential to facilitate or hinder clinical leadership.

Communication and teamwork were considered essential in ensuring effective clinical leadership.

\begin{abstract}
We work as a team. We can take turns-sometimes it's the doctor leading, sometimes it's a nurse or midwife; so that we can actually achieve quality service delivery. (Respondent 4)
\end{abstract}

Other respondents, however, identified the lack of interprofessional teamwork and conflict as barriers to clinical leadership. The narrative was strong that decision-making power was with doctors, and doctors did not value midwives' contribution to patient care at the bedside. Midwives suggested that support from health service managers could assist midwives to affirm their clinical leadership roles among other professionals, especially doctors.

There is friction between doctors and nurses. When you (contribute) something as a midwife, and you do not have a specialisation, doctors do not receive it. Sometimes you have to phone the provincial office for somebody to support you. (Respondent 6) You know how knowledgeable midwives can be, but most of the power for clinical decisions have been given to doctors. Whatever decision or suggestion you make, just because the doctor was not there, he can delay treatment for the patient. (Respondent 7)

\section{Enablers and barriers to clinical leadership at the level of the individual healthcare provider}

At the individual healthcare provider level, two major themes were identified: competencies required for effective clinical leadership, and the lack of balance between clinical leadership and managerial responsibilities.

\section{Competencies required for effective clinical leadership}

Two major skill sets were identified as fundamental for effective clinical leadership: first, clinical expertise, and second, leadership competencies. Additional domains of leadership competencies include personal, relational and organisational skills.

It doesn't have to be you (clinical leader) all the time, but you can delegate, allocate some tasks to the staff in your department. (Respondent 7)

For clinical leadership, you need somebody who has skills for mentorship so that she is able to transfer the skills and knowledge to other people, especially the new people that are coming into the department. (Respondent 4)

Midwives also identified a lack of essential skills as a barrier to clinical leadership.

They (clinical leaders) are to be leading by example even with the clinical expertise, but you'll find that they lack so much. (Respondent 5)

Clinical leaders need to be confident to provide clinical leadership, but many lack confidence, especially in front of medical doctors. (Respondent 6)
Balance between managerial and leadership roles

Midwives noted that formally appointed clinical leaders struggled to balance between managerial and clinical leadership roles. Some respondents, with workshop participants concurring, responded as follows:

There's a lack of balance between duties.... Operational managers are more managers than clinical leaders. (Respondent 3)

Management calls you if you do not attend a meeting. You don't know if you should be in your unit (at the bedside) or listen to management (and be in meetings). (Workshop participant)

\section{DISCUSSION}

The transitioning health system of Democratic South Africa prioritised making health services available and accessible to all South Africans. ${ }^{34} 35$ As health services have become available and accessible, the focus has turned towards ensuring the provision of quality care. It is within the context of ensuring quality care that the call for effective clinical leadership has arisen. ${ }^{34} 35$ This study sought to evaluate the enablers and barriers to clinical leadership in labour wards of district hospitals in KZN, South Africa.

This study confirms a range of findings already identified in the literature emerging from high-income countries (HICs), where clinical leadership is better developed. ${ }^{36-38}$ The enablers and barriers to clinical leadership identified in HICs are transferable to developing health systems, such as in the South African context, and in other LMICs.

In this study, enablers and barriers to clinical leadership are reported to arise from emergent dynamic interactions within the labour ward and the broader health system, and are located at policy, organisational, team and individual healthcare provider levels. In a health system that is still maturing, ${ }^{12}$ policies aimed specifically at clinical leadership would provide a broad context and strategy to ensure that frameworks and guidelines exist to guide the roles and responsibilities of clinical leadership, and the training and development required to ensure effective clinical leadership. ${ }^{39-41}$ Having policies on clinical leadership might help to address the enablers and hindrances identified at each of the levels.

Effective clinical leadership requires an enabling environment of care, ${ }^{42-46}$ which comprises sufficient and adequately trained core staff supported by essential supplies and equipment to provide basic and emergency care. ${ }^{478}$ An enabling environment enables teams to provide safe, effective and quality patient care, and provides professional development.

Positional clinical leaders are mandated to uphold clinical standards, enable professional development and ensure an enabling environment for optimal bedside care. ${ }^{26} 4950$ Visibility is an important relational skill required to ensure optimal patient care. $^{265152}$ The shortages of positional clinical leaders makes it difficult for the few available positional clinical leaders to be visible in labour wards and to provide effective clinical leadership. ${ }^{25}$

In this study, it was reported that positional clinical leaders struggle to balance between clinical leadership and managerial roles, consistent with other studies. ${ }^{25} 53$ The struggle to balance roles may be exacerbated by a lack of policy on clinical leadership training and development, contributing to role confusion, or by increased workloads, resulting from a shortage of health workers, leading to inadequate clinical leadership. ${ }^{25}$ Midwives in this study supported the view that the title used for formally appointed positional clinical leaders might contribute to a poor understanding of the concept of clinical leadership. Hence, 
including positional clinical leaders in identifying the enablers and barriers to clinical leadership weighted more on managerial issues, rather than leadership, which might have been identified by frontline healthcare providers, introducing a limitation to the study.

Clinical leaders require support to exercise and develop their clinical leadership roles. Mentoring and supervision empower clinical leaders to apply new skills to clinical situations, and provide an opportunity to share and discuss clinical cases with other professionals, enhancing teamwork and better patient care. ${ }^{5455}$ This finding is supported by previous research which acknowledged the role of structural support for the development of clinical leadership skills. ${ }^{50}$

An environment where all healthcare providers could effectively contribute to patient care was seen to be an essential factor influencing clinical leadership in labour wards. ${ }^{26}$ Communication and teamwork facilitate cohesion, development of interpersonal skills of the care team and interprofessional collaboration through discussion and reflection on practice. ${ }^{56}$

Midwives expressed that doctors did not value midwives' contribution to patient care, which is at odds with labour wards in district hospitals, where most deliveries are midwife-led. ${ }^{21}$ Additionally, it is at odds with the shared nature of clinical leadership which supports shared values, joint responsibility and mutual trust in patient care. ${ }^{42} 5758$ In such situations, midwives may become reticent to make the clinical decisions they are empowered to make, diminishing their contribution to optimal patient care. ${ }^{59}{ }^{60}$ Hence, the need for clear conceptualisations of clinical leadership and descriptions of clinical leadership roles to mitigate interprofessional conflict and confusion, promote effective teamwork and optimal patient care. ${ }^{425758}$

Competencies of every individual healthcare provider are required to ensure effective clinical leadership. ${ }^{61-63}$ The emphasis on clinical expertise to ensure effective clinical leadership is consistent with the emphasis found in other studies. ${ }^{526465}$ Clinical expertise in every member of the team enables shared clinical leadership and effective teamwork. ${ }^{66}$ Hence, the need for intentional and proactive clinical leadership development becomes more pronounced in such care settings, consistent with the findings in the literature. ${ }^{22} 25$ There is also a need for evidence-based models, to inform clinical leadership development.

\section{CONCLUSIONS}

Enablers and barriers to clinical leadership arise as a result of emergent dynamic interactions within the labour ward and the broader health system, located at policy, organisational, team and individual healthcare provider levels, with the policy context as the overriding factor framing the provision and development of clinical leadership.

Correction notice This article has been corrected since it was published Online First. The author's name has been changed from "Voce Silvia Anna" to "Anna Silvia Voce".

Acknowledgements Special thanks go to Professor Edgar Mhlanga (Provincial Specialist of Obstetrics and Gynaecology, Department of Health, Mpumalanga province) for his comments on the draft of this article.

Contributors SM (University of KwaZulu-Natal) planned the study, conducted interviews, performed data analysis and prepared write-up. VSA (University of KwaZulu-Natal) is the SM's PhD supervisor who made conceptual contributions and provided technical guidance throughout the writing processes (revising the article). Both authors read and approved the final manuscript.

Funding This paper is part of a doctoral study partly funded through a scholarship from the College of Health Sciences at the University of KwaZulu-Natal.

Competing interests None declared.

\section{Patient consent for publication Not Required}

Ethics approval Ethical approval to conduct the study was provided by the University of KwaZulu-Natal Biomedical Research Ethics Committee (Ref.: BE389/14) Permission to conduct the study was obtained from the KwaZulu-Natal Provincial Department of Health (Ref.: HRKM326/14).

Provenance and peer review Not commissioned; externally peer reviewed.

Data availability statement Data available in a public repository, https:// researchspace.ukzn.ac.za/handle/10413/16336 under CC BY-NC.

Open access This is an open access article distributed in accordance with the Creative Commons Attribution Non Commercial (CC BY-NC 4.0) license, which permits others to distribute, remix, adapt, build upon this work non-commercially, and license their derivative works on different terms, provided the original work is properly cited, appropriate credit is given, any changes made indicated, and the use is non-commercial. See: http://creativecommons.org/licenses/by-nc/4.0/.

\section{REFERENCES}

1 Coovadia $H$, Jewkes R, Barron $\mathrm{P}$, et al. The health and health system of South Africa: historical roots of current public health challenges. Lancet 2009;374:817-34.

2 Mills A. Health care systems in low- and middle-income countries. N Engl J Med 2014;370:552-7.

3 Department of Health. A District Hospital Service Package for South Africa. Pretoria, 2002. Available: http://www.kznhealth.gov.za/norms.pdf [Accessed 19 Nov 2018].

4 Wijeratne $D$, Weeks AD. Reducing maternal mortality in sub-Saharan Africa: the role of ethical consumerism. J Glob Health 2017;7:010309.

5 Moodley J, Fawcus S, Pattinson R. Improvements in maternal mortality in South Africa. South African Med J 2018;3:S4-S8.

6 Garenne M. Maternal mortality in Africa: investigating more, acting more. Lancet Glob Health 2015:3:e346-7.

7 Saving Mothers Giving Live. 2016 Annual Report: Reducing Maternal Mortality in SubSaharan Africa, 2016. Available: http://www.savingmothersgivinglife.org/docs/SMGL_ 2016_Annual_Report.pdf [Accessed 10 Oct 2018].

8 Louw HH, M'rithaaDK. Factors Causing Maternal Deaths At Level One Hospitals and Midwife Obstetric Units in the Western Cape, 2016.

9 Frøen F, Lawn J, Haezell A, et al. Ending Preventable Stillbirths An Executive Summary for The Lancet's Series Ending Preventable Stillbirths, 2016. Available: http://www. thelancet.com/pb/assets/raw/Lancet/stories/series/stillbirths2016-exec-summ.pdf [Accessed 13 Jun 2017].

10 Nzinga J, McGivern G, English M. Examining clinical leadership in Kenyan public hospitals through the distributed leadership lens. Health Policy Plan 2018;33(suppl_2):ii27-34.

11 National Committee for the Confidential Enquiry into Maternal Deaths. Saving Mothers 2011-2013: Sixth Report on the Confidential Enquiry into Maternal Deaths in South Africa. Pretoria, Tshepesa Press; 2014

12 Pattinson R, Rhoda N, Babies S. Saving Babies 2012-2013: Ninth Report on Perinatal Care in South Africa for the PPIP Group. Pretoria: Tshepesa Press; 2014.

13 Pattinson R. Reducing maternal deaths. S Afr J Obstet Gynaecol 2012;18:30-1.

14 Moodley J, Pattinson RC, Fawcus $S$, et al. The Confidential enquiry into materna deaths in South Africa: a case study. BJOG Int J Obstet Gy 2014;121:53-60.

15 Chopra M, Daviaud E, Pattinson R, et al. Saving the lives of South Africa's mothers, babies, and children: can the health system deliver? Lancet 2009;374:835-46.

16 Bateman C. Maternal and infant mortality expert hopeful for South Africa. S Afr Med J 2009:100:141-3.

17 Voce A, Bhana R, Monticelli F, et al. District Clinical Specialist Teams. In: Padarath A, Kling J, English R, eds. South African Health Review 2013/14. Durban, 2013:14. Available: http://www.hst.org.za/publications/South African Health Reviews/5 District Clinical Specialist Teams - SAHR2014.pdf [Accessed 24 May 2017].

18 Pattinson R, Sithembiso V, Hardy B. Overview. In: Pattinson R, ed. Saving babies 20062007 sixth report on perinatal care in South Africa. Pretoria, 2009:1-39. Available: http://www.ppip.co.za/wp-content/uploads/Saving-babies-2006-7.pdf [Accessed 23 May 2017].

19 National Committee on the Confidential Enquieries into Maternal Deaths (NCCEMD). Saving mothers 2014-2016: seventh triennial report on confidential enquiries into maternal deaths in South Africa: short report. Pretoria,Tshepesa Press; 2018.

20 National Committee for the Confidential Enquiry into Maternal Deaths. Saving Mothers 1998: Confidential Enquiry into Maternal Deaths in south Africa. In: Saving Mothers. Pretoria: Tshepesa Press, 1999.

21 National Department of Health. Guidelines for maternity care in South Africa. A manual for clinics, community health centres and district hospitals. Pretoria: Department of Health, Republic of South Africa, 2015.

22 Doherty J. Improving Public Hospitals through Effective Clinical Leadership, Lessons from South Africa. Johannesburg, 2014. Available: https://www.wits.ac.za/media/ migration/files/cs-38933-fix/migrated-pdf/pdfs-5/Clinical leadership report V4.pdf [Accessed 24 May 2017].

23 Doherty J. Leadership from 'below'? Clinical Staff and Public Hospitals in South Africa | Municipal Services Project, 2014. Available: http://www.municipalservicesproject. 
org/publication/leadership-below-clinical-staff-and-public-hospitals-south-africa [Accessed 22 May 2017].

24 Byrom S, Kay L. Midwifery leadership: theory, practice and potential. In: Downe S, Byrom S, Louise S, eds. Essential midwifery practice: leadership, expertise and collaborative working. 248. 1st ed. New Jersey: Willey-Blackwell, 2011.

25 Fenton K, Phillips N. Developing skills in clinical leadership for ward sisters. Nurs Times 2013;109:12-15.

26 Mianda S, Voce AS. Midwife conceptualizations of clinical leadership in the labor ward of district hospitals in KwaZulu-Natal, South Africa. J Healthc Leadersh 2018;10:87-94.

27 Corbin JM, Strauss AL. Basics of Qualitative Research: Techniques and Procedures for Developing Grounded Theory. California: Sage Publications, 2015.

28 Creswell JW. Qualitative inquiry and research design: choosing among five approaches. 3rd ed. SAGE Publications, 2013.

29 Edwards R, Holland J. What Is Qualitative Interviewing? 1st ed (Edwards R, Holland J, eds.). London: Bloomsbury Academic, 2013.

30 Bowen GA. Naturalistic inquiry and the saturation concept: a research note. Qual Res 2008;8:137-52.

31 Saunders B, Sim J, Kingstone T, et al. Saturation in qualitative research: exploring its conceptualization and operationalization. Qual Quant 2018;52:1893-907.

32 Creswell J, Miller DL. Determining validity and reliability in qualitative inquiry. Theory Pract 2010;39:124-30.

33 Lincoln YS, Guba EG, Pilotta JJ. Naturalistic Inquiry. Beverly Hills, CA: Sage, 1985: 9. 438-9.

34 Dhai A. Healthcare reform in South Africa: a step in the direction of social justice. S Afr I Bioeth Law 2011:4.

35 Schaay N, Sanders D, Kruger V. Overview of Health Sector Reform in South Africa. London, 2011. Available: www.hlsp.org [Accessed 13 Feb 2019].

36 Fealy GM, McNamara MS, Casey M, et al. Barriers to clinical leadership development: findings from a national survey. J Clin Nurs 2011;20:2023-32.

37 Bagnall P. Facilitators and Barriers to Leadership and Quality Improvement: The King's Fund Junior Doctor Project. London, 2012. Available: https://www.kingsfund.org.uk/ sites/default/files/facilitators-barriers-leadership-quality-improvement-pippa-bagnallleadership-review2012-paper.pdf [Accessed 11 Feb 2019].

38 Health Service Executive. National Nursing and Midwifery Clinical Leadership Development Needs Analysis HSE Executive Report. Dublin, 2010. Available: https:// www.choiceforum.org/docs/clinicaldes.pdf [Accessed 23 May 2017].

39 World Health Organization (WHO). Everybody Business: Strengthening Health Systems to Improve Health Outcomes. WHO's Frame Work for Action. Geneva, 2007. Available: https://www.who.int/healthsystems/strategy/everybodys_business.pdf

40 Denis J-L, van Gestel N, Van GN. Medical doctors in healthcare leadership: theoretical and practical challenges. BMC Health Serv Res 2016;16:46-56.

41 Waring J. Restratification, hybridity and professional elites: questions of power, identity and relational contingency at the points of 'Professional-Organisational Intersection'. Sociol Compass 2014;8:688-704.

42 Rankin J, Matthews A, Russell M, et al. Clinical leadership and effective nursing teams. J Nurs Heal Care 2016;4.

43 Asegid A, Belachew T, Yimam E. Factors influencing job satisfaction and anticipated turnover among nurses in Sidama zone public health facilities, South Ethiopia. Nurs Res Pract 2014;2014:1-26.

44 Daly J, Jackson D, Mannix J, et al. The importance of clinical leadership in the hospital setting. J Healthc Leadersh 2014;6:75-83.
45 McNamara MS, Fealy GM, Casey M, et al. Mentoring, coaching and action learning: interventions in a national clinical leadership development programme. J Clin Nurs 2014;23:2533-41

46 Kos S, Kavanagh J. Clinical Leadership- the role of clinicians in EHealth reform. 2011. West Australia: Microsoft Australia, 2011.

47 Duffield CM, Roche MA, Blay N, et al. Nursing unit managers, staff retention and the work environment. J Clin Nurs 2011;20:23-33.

48 Kieft RA, de Brouwer BBJM, Francke AL, et al. How nurses and their work environmen affect patient experiences of the quality of care: a qualitative study. BMC Health Serv Res 2014;14:249.

49 Armstrong SJ, Rispel LC, Penn-Kekana L. The activities of hospital nursing unit managers and quality of patient care in South African hospitals: a paradox? Glob Health Action 2015;8:26243.

50 Rankin J, McGuire C, Matthews L, et al. Facilitators and barriers to the increased supervisory role of senior charge nurses: a qualitative study. J Nurs Manag 2016:24:366-75.

51 Stanley D, Blanchard D, Hohol A, et al. Health professionals' perceptions of clinical leadership. A pilot study. Cogen Med 2017;4

52 Stanley D, Cuthbertson J, Latimer K. Perceptions of clinical leadership in the St John ambulance service in WA. Response 2013;39:31-7.

53 Stanley D. Role conflict: leaders and managers. Nurs Manage 2006;13:31-7

54 Zainal Abiddin N. Mentoring and coaching: the roles and practices. J Hum Resour Adult Learn 2006:107-16.

55 Tomlinson J. Using clinical supervision to improve the quality and safety of patient care: a response to Berwick and Francis. BMC Med Educ 2015;15:1-8.

56 Smith T, Fowler-Davis S, Nancarrow S, et al. Leadership in interprofessional health and social care teams: a literature review. Leadersh Health Serv 2018;31:452-67.

57 Al-Sawai A. Leadership of healthcare professionals: where do we stand? Oman Med $\mathrm{J}$ 2013;28:285-7.

58 National Health Services Institute for Innovation and Improvement. Shared leadership underpinning of the MLCF. In: Enhancing Engagement in Medical Leadership. Coventry, 2009. Available: http://www.leadershipacademy.nhs.uk/wp-content/ uploads/2012/10/776bc9c27b6e8741d0ff42e593ba44cf.pdf [Accessed 24 May 2017].

59 Giltinane CL. Leadership styles and theories. Nurs Stand 2013;27:35-9.

60 Patton C. Conflict in health care: a literature review. Int J Healthc Adm 2014;9.

61 Lett M. The concept of clinical leadership. Contemp Nurse 2002;12:16-21 http:// www.ncbi.nlm.nih.gov/pubmed/12013513

62 Stanley DJ. Clinical leadership and innovation. J Nurs Educ Pract 2012;2.

63 Jonas S, McCay L, Keogh B. The importance of clinical leadership. In: Swanwick T, McKimm J, eds. ABC of Clinical Leadership. 1st ed. Oxford: Blackwell Publishing Ltd 2011: 1-3.

64 Mendis D, Paton C. Perceptions of clinical leadership amongst West Midlands registrars. Int JnI Leadership in Pub Serv 2014;10:108-22.

65 Trimmer W. The way things are done around here: perceptions of clinical leadership in mental health nursing, 2007. Available: http://repository.digitalnz.org/system/uploads/ record/attachment/195 [Accessed 24 May 2017].

66 Power LFC. Leadership: an influence process. Int J Manag Business Adm 2012;15. 